$5^{\text {th }}$ International $/ 11^{\text {th }}$ Construction Specialty Conference

$5^{e}$ International $/ 11^{e}$ Conférence spécialisée sur la construction

Vancouver, British Columbia

June 8 to June 10, 2015 / 8 juin au 10 juin 2015

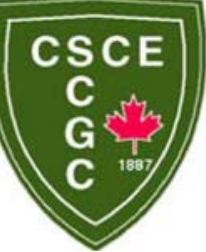

\title{
ELECTRONIC DOCUMENT MANAGEMENT SYSTEMS FOR TRANSPORTATION CONSTRUCTION INDUSTRY
}

\author{
Fangyu Guo ${ }^{1,4}$, Charles T. Jahren ${ }^{2}$, and Yelda Turkan ${ }^{3}$ \\ ${ }_{1}^{1}$ Department of Civil, Construction, and Environmental Engineering, lowa State University, US \\ ${ }^{2}$ Department of Civil, Construction, and Environmental Engineering, lowa State University, US \\ ${ }^{3}$ Department of Civil, Construction, and Environmental Engineering, lowa State University, US \\ ${ }^{4}$ fangyu@iastate.edu
}

\begin{abstract}
The concept of Civil Integrated Management (CIM) was developed to facilitate better utilization of data and information that would enable effective decisions for transportation agencies. It is important to select appropriate intelligent technologies or tools and use them efficiently. Moreover, data needs to be collected, stored, and managed wisely so that it could be used throughout the life cycle of a transportation facility and even for the next reconstruction cycle. This makes it necessary for agencies to have electronic document management (EDM) systems, so that they can manage and share their data with other stakeholders in an efficient manner. Though EDM systems have been implemented and their benefits are well understood in the building construction industry, they are not as common in the transportation design and construction industry, and there are only a few leader state DOTs implementing EDM at agency wide level. Since there are differences between the building and the transportation industry, it is desirable to analyze early examples of implementation from the transportation industry in order to achieve further progress. The purpose of this paper is to present and analyze current state of the EDM systems within the state DOTs that lead with regard to EDM implementation. During a United States National Cooperative Highway Research Project Domestic Scan effort, seven state DOTs and their contractors collaborated to present their extensive experience on CIM related practices and tools. Of these seven, four distinguished themselves with leadership in the area of EDM systems implementation while others were leaders in other areas. In this paper, those four agencies who are leaders with regard to the EDM systems implementation are analyzed and their practices are documented in detail.
\end{abstract}

\section{INTRODUCTION}

Electronic Document Management (EDM) systems have become more crucial to the transportation industry as more advanced tools and automated process have been adopted. Prior to the adoption of EDM systems, piles of paper plans or other documents had to be handed back and forth within agencies and/or between various parties. Considerable time and cost were spent on printing out and shipping hard copy documents during the duration of a typical project. Nowadays, with the adoption of EDM systems, personnel form various stakeholders can easily submit documents to the same platform, and other users involved with the project or a particular task can view the submitted documents and provide comments, concurrence and approvals. Furthermore, certain engineering products, such as 3D models must be delivered electronically, because they cannot be easily converted to hard copies. EDM systems eliminate the need for printing and shipping documents among various parties (Sulankivi et al. 2002). Moreover, the 
documents or models might be stored in the system as permanent record if necessary, so that stakeholders can extract and use them in the future.

Especially after the release of Moving Ahead for Progress in the $21^{\text {st }}$ Century (MAP 21) legislation, many leading transportation agencies started using various advanced tools such as EDM system, 3D modeling, GPS, GIS, automatic machine guidance and others. Also, programs such as Every Day Count (EDC), which is facilitated by Federal Highway Administration (FHWA) in the United States, is meant to encourage the adoption of various innovative methods and tools. E-construction, one of the topics under EDC-3, specifically addresses the importance and benefits of using EDM systems (FHWA 2015).

This paper presents the results associated with the EDM system obtained from the National Highway Cooperative Research Program (NHCRP) Domestic scan project 13-02 Advances in Civil Integrated Management (CIM). The final report of this project is expected to be released during the second or third quarter of 2015. During this scan study, panel members visited seven leading states to explore current practices related to CIM. Content analysis method was adopted to analyze the EDM system related presentations and documents provided by host agencies. It is found that EDM systems, as one of the major components of CIM, are helpful in increasing communication efficiency among various parties and retaining data integrity and transparency during the project duration. EDM systems adopted by four transportation agencies and their functionalities are analyzed in this paper.

\section{BACKGROUND}

Common tools used by agencies or companies to support electronic collaboration include document management, file sharing, emails, calendars, discussions, polling, and instant messaging (Munkvold and Zigurs 2005). Study results from 2003 indicated that about half of the larger contractors were already using project collaboration technologies to some extents in the US (Issa, Flood, and Caglasin 2003).

During the project duration, a large number of documents are usually produced, such as design drawings, schedules and estimates, meeting minutes, bill of quantities, and others. There has been several attempts at the standardization of those documents involved various industrial organizations in various countries. As word and CAD applications became more commonly adopted in the industry, traditional hard copies began to be replaced with digital forms of documents which can be distributed out by email or other tools. Subsequently, the EDM systems evolved with the capability to retain all of the latest documents that were generated during a project on the same web server (Björk 2006). Such systems could be created by an agency or company's in-house staff, project participants, or a third party (Bjork 2003), and these systems were either developed at project/team level or at enterprise level (Munkvold and Zigurs 2005).

The role of metadata in EDM systems is important, as the directory structures embedded within the metadata could help mitigate potential damage that would result from loss of data or documents. Also, document searches become easier and more precise with the directory structure that can be devised from metadata (Tough and Moss 2003). The standardization of metadata and data storage is very important, as it could provide considerable convenience for downstream users (Bjork 2003).

Based on the case studies conducted by Sulankivi et al. (2002), the use of EDM systems resulted in 29 work days' savings and avoided 1700 days of delay in information distribution, which together saved 17,300 USD for one single project in Finland. Major qualitative benefits of using EDM systems include easier document distribution and publishing, easy access to the latest updated versions of documents, and easy access to real-time information (Sulankivi et al. 2002). On the other hand, there are some challenges associated with the use of EDM systems. In a study conducted by Mohamed and Stewart (2003), it was indicated that considerable training and support related to the EDM system would be necessary for users. Becerik (2004) indicated that lack of studies on illustrating the EDM systems' benefits resulted in the slow development and popularization of the EDM systems. In addition, Munkvold and Zigurs (2005) recommended that the EDM systems should be developed in a way that users can easily adapt to them. Otherwise, users might tend to select the older ways of performing work tasks. Also, guidelines and support should be developed to instruct new users about how to implement such systems. 


\section{METHODOLOGY}

A content analysis approach was adopted as the major methodology to establish a better understanding of current practices on the implementation of EDM systems. The analyses were conducted as part of US Domestic Scan Project 13-02 that was entitled Advances in CIM which is managed under the auspices of the NCHRP 20-68A U.S. Domestic Scan Program. Scan team members were chosen from among leading state DOTs who have interest in adopting CIM related practices and tools in addition to the FHWA representatives. Scan team members, along with a subject matter expert (SME, the second author) and his assistants (the first and third authors), developed a set of amplifying questions relevant to the topics of interest including EDM system. These questions were then sent to the target agencies and their contractors and consultants. When scan team members visited the leading state DOTs, presentations were provided by the host agencies in response to the questions. Detailed notes were recorded during the presentations and interactions between scan panel members and host agencies. In addition, supplemental documents were also provided by the host agencies to assist panel members in better understanding their usage of certain tools. These notes and supplemental documents were systematically analyzed to provide the findings.

As previously mentioned, EDM is one of the major components of CIM. Various agencies or companies are using various EDM systems produced either by their in-house employees, project partners or commercial software developers. Four state DOTs who served as host agencies in this study were selected for detailed analysis, as they have relatively mature EDM systems and extensive experience in using such systems. Presentations and documents related to EDM were reviewed using the content analysis method (Elo and Kyngäs 2008, Neuendorf 2002). For lowa DOT case study, additional documents obtained from lowa DOT's official website were also analyzed. In Section 4, the content analysis results associated with the EDM systems used in four target agencies are summarized and presented.

\section{FINDINGS}

\subsection{Utah DOT}

Utah DOT is currently using an application called Interchange which was developed using a Microsoft SharePoint platform. This program contains segments that were developed for different groups of users and also for different phases of projects. Additional segments are still under development. The program can not only be used by DOT personnel, but also can be used by their local contractors. This construction portal is adopted for 18 construction projects so far, and Utah DOT is planning to have all construction projects use this portal by the end of 2015. Some of the major capabilities provided by this program include document submission, task management, meeting minutes, and design review.

Through this program, various groups are able to submit their documents or design models to the same platform. When documents are being submitted, users can make selections with regard to the document filter, type, and subtype. This initial setup selection allows documents to be better organized within the system, making it easier and faster to search and manage documents. Users can assign other attributes to documents such as document event date and due date, phase, and others, and they can also specify which personnel within which group can receive the submitted document. Thus, when the documents are submitted successfully to the system, recipients are notified immediately.

Task management is another important function of this program. The schedule of various project-related tasks will be shown on a task calendar, which reminds users to perform the required tasks within the expected due dates. Tasks that are not completed yet are marked as open tasks, and users can view task status, due date, and responsible personnel for each open task. Users can not only view their own tasks, but also view tasks assigned to their group. Each open task is closed once it is finished.

Meeting minutes can also be tracked by this program. Meeting minutes can be recorded including other related information such as creator, meeting organizer, time, location, type, and attendees. At the same time, tasks can be assigned through meeting minutes if necessary. Utah DOT also tried to integrate this 
meeting minutes stored in this program with other applications such as the agency's email platform, however their attempt was unsuccessful due to data integration issues.

More importantly, this application allows for better tracking comments and responses, which makes design review process more effective. Usually in Utah, design reviews occur at $15 \%, 30 \%, 60 \%$, and $90 \%$ of design. Design packet that needs to be reviewed can be uploaded to the system based on the planned milestones. When uploading the design documents, the system provides various options such as which disciplines are supposed to review the submitted materials and by which date the review is expected to be completed. Then, reviewers can provide their comments before the designated due dates, and subsequent responses will be created by design documents creators to address those comments. Each review document will be coded by different colors based on each division's review status (e.g. not needed, no response, in progress, complete, etc.). When changes are made to the design documents, the responsible disciplines will also be notified to review the changes. Usually, solutions to proposed comments will be addressed in the next design review meeting. Between each design review meeting, project managers will also have intermediate meetings to track the design progress. Exceptions might occur when design-builders ask for reduction of the number of submittals or meetings, and decisions for approving such requests will be made based on actual cases. Compared to the traditional design review process where piles of paper need to be handed back and forth, this digital communication method increases work efficiency and flexibility as well as maintaining a digital record of comments and responses occurred during design reviews.

\subsection{Michigan DOT}

Michigan DOT requires all electronic documents submitted through ProjectWise platform (Bentley Inc. 2014) and kept up to date. The only exceptions are delivery tickets for hot mix asphalt (HMA), concrete, and aggregates, which are stored as hard copy documents. Contractors are responsible to coordinate electronic document submittals by their subcontractors, suppliers, fabricators, and others that are involved in the construction process. Failure to upload documents to the system will result in delayed payment.

In order to better manage all submitted electronic documents, there are rules developed for document format, folder structures, and user authorizations. For example, contractors need to sort and place their files into the following folders: correspondence, materials, payrolls, shop drawings, and sub-contractor in box. Michigan DOT also provided training courses on the use of their EDM system for their contractors. In general, by using this electronic document management system, all information could be stored in one place and stakeholders have easy access to the most up to date project-related data.

The level of authorization is determined and monitored to ensure that personnel can access files when necessary while maintaining the security. For example, the project team cannot view information in contractors' inbox until the documents are submitted to the system. After contractors submit their documents, an audit trail will be attached to each file to achieve transparency. At the same time, restrictions are in place to prevent consultants or contractors who have competitive relationships from seeing each other's proprietary information or intellectual property.

Additionally, Michigan DOT uses and accepts digitally encrypted electronic signatures. Digitally encrypted electronic signatures are not scanned copies of handwritten ones, but rather electronic "objects" containing unique identities, password, and date/time. Most commonly adopted software for placing digital signatures for Michigan DOT EDM system is Adobe Acrobat. Each user will have a unique digital identification (ID) and password. Before placing an electronic signature, the user is required to provide his or her password. After the signature is placed digitally, the electronic document will become a signed original file which has the same legal effect as a paper document with a handwritten signature. In terms of signature validation, document recipient can check whether the electronic signature is placed by an expected signer and whether the document is sent from an agency/company's email account. If the signer has previously been verified by the system, there will be a green mark besides his or her signature. If the signer is new or cannot be verified, there will be a grey question mark besides his or her signature. 
Michigan DOT developed a detailed instruction document for placing and verifying digitally encrypted electronic signatures.

\subsection{New York State DOT}

New York State DOT requires all project related electronic documents to be stored in its EDM System which is built on a ProjectWise platform (Bentley Inc. 2014). Project related electronic documents to be stored normally included studies, permits, mapping, plan sheets, digital terrain models, reports, control, calculations, photos, correspondence, and other items. Emails involving project-related decisions are also expected to be stored in the system. DOT personnel, consultants, or contractors are required to follow specific instructions for document naming conventions, categories, and formats to ensure that the documents can be better organized, managed and retrieved.

This system contains DOT's DataSource and archive DataSource. DataSource is composed of various documents, folders, and their supporting database. Documents for active projects will be submitted to DOT's DataSource (NYSDOT 2006). There are specific rules developed for folder and subfolder structures within the DataSource. Official project records will be created based on electronic documents that reside in DOT's data source. After projects are completed, documents in DOT's DataSource will be moved to archive DataSource by a data manager, so that they become permanent records.

In order to ensure system security, access is limited to stakeholders who have proper authority based on work groups' responsibilities in various phases of a project. Read and write access will be given only to work groups that have active roles in a particular phase of a project. The rest of work groups without active duties will only have read access to a project. A regional data manager will be responsible for providing and changing each work group's access as the project moves forward. For non-department personnel such as consultants, contractors, and partners, only the minimum access required for their work will be provided. Employees of an outside company will only have read and write access to their company's designated folders.

All documents retained in the system are kept up to date. When a document is checked out, it means someone has downloaded the file for revision work and other personnel cannot make changes to this file at this stage. When the revision work is completed, this document will be checked backed into the system. Alternatively, users can select update server copy option to upload the most recent version to the server and keep the document checked out for further work.

Attributes assigned for each document are important for organizing and searching information. When searching for a document, documents with attributes matching the search criteria will be displayed for users. Thus, when uploading a document, all appropriate attributes applicable to a document should be assigned by the document creator. In addition, information could be automatically generated in MicroStation based on the document attributes resided in predefined tags.

The archiving process is another important part of data management. Documents that are used to create officially approved project records should be included in the archiving process. Data owners are expected to determine which documents should be kept and which documents can be deleted and then convey their decisions to the data manager. At each stage of a project (e.g. scoping, design, and construction), there are rules developed for key data that must be stored in the archive. When project is completed, all project data should be moved to the archive DataSource.

\section{$4.4 \quad$ lowa DOT}

lowa DOT's EDM system was developed using a Doc Express platform (Info Tech, Inc. 2015). lowa DOT offers instructions for contractors and suppliers about how to use this system for electronic file storage and sharing (lowa DOT 2015). Through this system, contractors can manage their contracts and associated documents systematically. They can view and sort their contracts based on their own preference, and they can choose to receive real-time notifications (e.g. ready to be processed, rejected, etc.) or request a summary report for all of their contracts and/or ones added in their favorite lists. Under each contract, they can select various virtual "(file cabinet) drawers" named based on document 
categories for managing their documents, including Contract Documents, Pay Items, Payrolls, Contract Modifications, Working, Shop Drawings, and Signatures.

Documents are submitted to their appropriate drawers. DOT and prime contractors can open the submitted documents in the drawers to which they have access. Subcontractors and suppliers can only open documents submitted by their own companies, though they can see a larger list of documents. Documents will be electronically signed when submitters check the electronic signature box. Once documents are submitted to the system, no changes can be made to the documents' contents. Comments can be added to those documents by other personnel or document creators.

The Contract Documents drawer is the place for storing documents related to a particular contract. This drawer is mostly used by DOT personnel, but there are also cases where the prime contractor needs to submit documents to this drawer. DOT users or the prime contractor can make comments on the submittals in this drawer. Likewise, the Pay Items drawer is used for storing pay item documents associated with a particular contract. DOT personnel mark the submittals as received or audited. The status of audited indicates that the materials users have audited the item and no further checking is needed.

Contract modifications (or change orders) are made in the FieldManager application (Info Tech, Inc. 2015) and then submitted to the Contract Manager drawer. Once contract modifications are submitted to the system, users who have access to this drawer will receive notifications immediately. The prime contractor needs to review the submitted documents and provide signatures if they approve those submittals. All associated activities could be tracked down through the system. The time, date, and personnel's role associated with each transaction are visible to users with access. After all signatures have been collected, contract modification will be approved in FieldManager.

Payrolls sent from subcontractors can be certified by the prime contractor and then submitted to the Payrolls drawer by the prime contractor. The submitter can open and view the submitted payroll documents, but users associated with the prime contractor can only view the list of submittals. Also, only selected DOT personnel involved with the contract are given the access to those payrolls.

The Working drawer is designed for sharing documents that are produced during working process and should be continuously updated until the final version is completed. Once a document is finalized in the Working drawer, it will be published by a DOT user to its appropriate location (a specific drawer). As for the Shop Drawings drawer, it is the place to which shop drawings should be submitted. The prime contractor is the only user authorized to submit drawings to this drawer. Personnel who are supposed to review the documents can either open or download the drawings in this drawer and make comments if necessary. The Signature drawer is mostly used by DOT personnel and contains documents that need to be signed by one or more people.

\subsection{Discussion and Comparisons}

Generally, the EDM products described above are designed with three different approaches which could be categorized as:

- General purpose workflow and file storage solution (e.g. Microsoft SharePoint Platform)

- Document access solution originally developed to meet the needs of design groups (e.g. ProjectWise)

- Document management solution designed mainly for transportation construction agencies (e.g. Doc Express)

The original purpose and approach for the development of these products were somewhat different, so they all come with their own unique capabilities, characteristics, and IT support demands. However, there are common functionalities shared, such as:

- Document submission

- Electronic signatures

- Document access based on the predesignated level of authority 
- Document sharing

- Document format and structure standardization

- Document searching based on the assigned attributes

- Creation and modification tracking

- Instant notice to related users

These functionalities appear to be adequate for supporting most transportation agency needs for electronic document management. Moreover, the communication process between various stakeholders becomes easier and faster when an EDM system is implemented. Despite the differences of these EDM implementation approaches, they have proven to be efficient in organizing and managing electronic documents within the same agency and exchanging documents amongst the agency, designers and contractors. In cases where then current products could not support an agency's needs, modifications were made by collaborating with software developers or tasking in house or consultant programmers to produce a solution addressing agency needs. Overall, stakeholders provided positive feedback on the adoption of EDM tools for the purpose of data storage and exchange. In one case, a contractor trade association proactively encouraged the use of the EDM tool for file exchange.

During the application of these EDM tools, some challenges were also identified as below: (1) interoperability issues between various software applications and hardware are always challenging; (2) An insufficient budget is often initially allocated for purchasing and updating hardware and software applications; (3) It is difficult for agencies to decide whether to use an existing commercial product or to develop a customized in-house product; (4) Stakeholders outside the agency, such as contractors, might have difficulty accessing the system due to stringent protocols required to penetrate agency firewalls; and (5) It is often be difficult to obtain quick and effective specialized IT assistance within the unit that needs help, especially if IT support has been highly centralized (for example provided on a state wide basis).

\section{CONCLUSIONS AND RECOMMENDATIONS}

The EDM systems have become more commonly used in the transportation construction industry, as they help to better manage and share documents produced throughout the project life cycle. Currently, various companies or agencies are using various EDM systems which might be produced by their in-house staff, project partners, or third parties such as a software vendor. All these products are designed to help improve the digital communication process and increase work efficiency by reducing the time spent in handing hard copies of documents among various parties. Each product might have its unique characteristics and ways to support its users during the project duration or daily company operations. The intention of this study is not to conclude which product is better than the others but rather to present the functionality and real practice of EDM systems adopted within some leading transportation agencies.

It is important for agencies and companies to determine which product might fit their demand better or if they need to develop their own unique product. No matter which product they are using or planning to use, critical issues need to be considered include standardization of document submission and sharing, proper level of user authorizations, long term storage, training programs, IT support, and others. Essentially, the EDM systems are tools that can make the work process easier and faster. Discussions with host agencies indicated that as employees become more familiar with the systems, their work efficiency increases and they come to greatly prefer the EDM systems to the traditional work process.

Nowadays, technologies are evolving quickly. The transportation design and construction industry, which has not adopted EDM systems as fast as the building design and construction industry, can review these case studies and select the tools that will increase their productivity and quality of work. The EDM systems are basic tools that should be used not only at project level, but can also be useful at enterprise level. Feedback from using current EDM systems should be kept and sent to program developers for further improvement. Furthermore, more communication should occur among agencies or companies, software developers, and researchers to share lessons learned and exchange ideas. Collaboration between researchers, developers and industry practitioners to deliver more useful products and 
disseminate best practices can be helpful. Together, with everyone's efforts, technologies can continue to be improved and become more beneficial for the entire transportation design and construction industry.

\section{Acknowledgements}

Most of the material in this paper is based on presentations and documents obtained during Scan 13-02 Advances in Civil Engineering Management (CIM) supported by National Cooperative Highway Research Program (NCHRP) 20-68A US Domestic Scan Program. Scan team members included John Adam of lowa DOT, Katherine Petros and Brian Cawley of the US Federal Highway Administration, Rebecca Burns of Pennsylvania, Duane Brautigam of Florida DOT, Julie Kliewer of Arizona DOT, John Lobbestael of Michigan DOT, Stan Burns and Randall R. Park of Utah DOT, David Jeong of lowa State University; the scan team was supported by Harry Capers, Jake Almborg, and Melissa Jiang of Aurora and Associates, P.C. Lawrenceville, NJ. Their assistance in analyzing the information obtained from the visits is gratefully acknowledged. We would like to sincerely convey our thanks for the support provided by the lowa, Michigan, Utah, and New York State DOTs.

\section{References}

Becerik, Burcin. 2004. "A review on past, present and future of web based project management \& collaboration tools and their adoption by the US AEC industry." International Journal of IT in Architecture Engineering and Construction 2: 233-248.

Bentley Inc. (2014). "ProjectWise: AECO Information Management and Project Collaboration Software." Online: http://www. bentley.com/en-US/Products/projectwise+project+team+collaboration/, Accessed: Jan. 28, 2015.

Bjork, Bo-Christer. 2003. Electronic document management in construction-research issues and results. ITcon.

Björk, Bo-Christer. 2006. "Electronic document management in temporary project organisations: Construction industry experiences." Online Information Review 30 (6): 644-655.

Elo, Satu, and Helvi Kyngäs. 2008. "The qualitative content analysis process." Journal of advanced nursing 62 (1): 107-115.

Federal Highway Administration. 2015. "e-Construction." Online: http://www.fhwa.dot.gov/everydaycounts/edc-3/econstruction.cfm, Accessed Jan. 20, 2015.

Info Tech, Inc. (2015). "Doc Express, Paperless Contracting." Online: https://docexpress.com/login?return_to=\%2F, Accessed: Jan. 28, 2015.

Info Tech, Inc. (2015). "FieldManager, Construction Management." Online: https://www.infotechfl.com/field_manager. Accessed: Jan. 28, 2015.

lowa DOT (2015). "Doc Express Instruction Guide for Contractors and Suppliers." Online: http://www.iowadot.gov/Construction_Materials/contractor_guide.pdf, Accessed: Jan. 28, 2015.

Issa, R. R. A., I. Flood, and G. Caglasin. 2003. "A survey of e-business implementation in the US construction industry." Journal of Information Technology in Construction 8: 15-28.

Mohamed, Sherif, and Rodney A. Stewart. 2003. "An empirical investigation of users' perceptions of webbased communication on a construction project." Automation in construction 12 (1): 43-53.

Munkvold, Bjørn Erik, and Ilze Zigurs. 2005. "Integration of e-collaboration technologies: Research opportunities and challenges." International Journal of e-Collaboration (IJeC) 1 (2): 1-24.

Neuendorf, K. A. (2002). The content analysis guidebook. Sage.

New York State DOT (2006). "Project Development Manual Appendix 14, Project Data Management." Online: https://www.dot.ny.gov/divisions/engineering/design/dqab/dqab-repository/pdmapp14.pdf, Accessed: Jan. 28, 2015.

Tough, Alistair, and Michael Moss. 2003. "Metadata, controlled vocabulary and directories: electronic document management and standards for records management." Records Management Journal 13 (1): 24-31.

Sulankivi, K., Lakka, A., and Luedke, M. 2002. Project management in the concurrent engineering environment. VTT Publications. Technical Research Centre of Finland. Online: http://www2.vtt.fi/inf/pdf/publications/2002/P470.pdf, Accessed Jan. 23, 2015. 